\title{
Dysphagia lusoria
}

\section{Julie Dandelooy MD, Jan P.M. Coveliers MD, Paul E.Y. Van Schil MD PhD, Sébastien Anguille MD}

Previously published at www.cmaj.ca

A 76-year-old woman presented with difficulty swallowing solid food and with shortness of breath. Her symptoms had developed over several months. She did not have odynophagia, had not experienced weight loss and did not drink alcohol or smoke. Her physical exam was unremarkable.

Barium esophagography showed a posterior oblique indentation of the proximal esophagus slightly above the level of the aortic arch, suggestive of an aberrant right subclavian artery compressing the esophagus (Figure 1A). The diagnosis was confirmed by a contrast-enhanced computed tomography scan, which showed an aneurysmatic right subclavian artery originating as the last branch of the aortic arch. The artery followed a retro-esophageal course to cross the midline, resulting in a prominent compression and shift of the patient's esophagus. This aberrant anatomy was clearly visible in computed tomography images reconstructed 3dimensionally using a volume-rendering technique (Figure 1B).

An aberrant right subclavian artery is a relatively common congenital anomaly. It has a prevalence of up to $1.8 \%$. About a third of people with this anatomic variant experience symptoms. Dysphagia is experienced in $90 \%$ of such cases, whereas dyspnea, as in our patient, is less common. ${ }^{1}$ Dysphagia secondary to extrinsic esophageal compression by an aberrant right subclavian artery is known as dysphagia lusoria. This term dates back to the first description of the condition in 1794 by David Bayford, who called it "lusus naturae," meaning "freak or jest of nature."

'The late-onset presentation in our patient is not uncommon. Contributing factors for the development of symptomatic dysphagia in elderly persons include decreased flexibility of the esophagus itself associated with aging, and increased

From the Department of Thoracic and Vascular Surgery (Dandelooy, Coveliers, Van Schil) and the Department of Internal Medicine (Anguille), Antwerp University Hospital, Antwerp, Belgium

Cite as CMAJ 2009. DOI:10.1503/cmaj.081651 esophageal compression caused by progressive aneurysmal dilatation of the aberrant artery or arteriosclerosis-induced rigidity of the vessel wall. ${ }^{3}$ Our patient's dyspnea was likely related to external tracheal compression by the aberrant artery or compression of the pulmonary artery. The latter is common in patients with an aneurysmal dilatation of the aberrant right subclavian artery associated with a Kommerell diverticulum. We performed a right carotico-subclavian bypass. Our patient reported complete resolution of her pulmonary symptoms and dramatic improvement of her dysphagia after the surgery.

\section{REFERENCES}

1. Levitt B, Richter J. Dysphagia lusoria: a comprehensive review. Dis Esophagus 2007;20:455-60.

2. Bayford D. An account of a singular case of obstructed deglutition. Memoirs Med Soc London 1794;2:275-86.

3. Kantarceken B, Bulbuloglu E, Yuksel M, et al. Dysphagia lusorium in the elderly: a case report. World J Gastroenterol 2004;10:2459-60. 